\title{
The SENCO Role in Post-Primary Schools in Ireland: Victims or agents of change?
}

Johanna Fitzgerald ${ }^{1}$ and Julie Radford ${ }^{2}$

${ }^{1}$ Department of Educational Psychology, Inclusive and Special Education, Mary Immaculate College, Limerick, Ireland

${ }^{2}$ Department of Psychology and Human Development, University College London, Institute of Education, London, UK

Corresponding author:

Johanna Fitzgerald, Lecturer in Special Education

Department of Educational Psychology, Inclusive and Special Education,

Mary Immaculate College,

South Circular Road, Limerick, Ireland.

Tel: 0035361204517

Email: Johanna.fitzgerald@mic.ul.ie 


\section{The SENCO Role in Post-Primary Schools in Ireland: Victims or agents of change?}

\section{Abstract}

This paper aims to consider the role of the Special Educational Needs Coordinator (SENCO) in mainstream post-primary schools (12-18 years) in Ireland. Little is known of the role in the Irish context and it is hoped that this research will inform policy. The Irish educational landscape has witnessed seismic change since the early 1990's with further transformation on the horizon. The SENCO role is a recent phenomenon in Irish schools and while much is known of the role internationally, Irish SENCOs tend to operate in a policy vacuum. This paper draws on research with a purposive sample of twenty-seven SENCOs in Ireland. A lengthy postal questionnaire served as the method of data collection, where both quantitative and qualitative data were collected. Findings reveal the complexity of the role in an evolving and dynamic education system. SENCOs continue to fulfil largely operational roles and are limited in their capacity to effect change in inclusive practice from a whole-school perspective. Lack of formal recognition of the SENCO role has led to its ad-hoc development in a policy landscape devoid of any recognition of the magnitude of the role. This research makes the case for the formalisation of the role at policy level and recognition of the need to develop the SENCO as strategic leader, firmly situated within the management structure in schools. Otherwise, Irish SENCOs risk being victims rather than agents of change.

Keywords: SENCO role; Post-primary; Inclusive Leadership; Change Agent 


\section{Background}

The policy context in Ireland does not formally recognise the SENCO role and offers little guidance as to how it should be enacted. Its only reference can be found in the Inclusion of Students with Special Educational Needs Post-Primary Guidelines (DES, 2007) where it is assumed the principal will have overall responsibility for special education provision, but may devolve duties to a member(s) of the special educational needs team, if a team exists. Until recently, no recognition of the time required to undertake the role was reflected in policy. Schools are now advised to allocate time for duties from the schools' quantum of additional resource hours (DES, 2014). Moreover, as the role has not been formalised it remains at the discretion of schools to include such a position in its schedule of posts of responsibility. This presents a challenge as to how the role is conceptualised and enacted in schools.

Coordination of special education provision in Ireland is deeply embedded in deficit views of disability (National Council for Special Education, 2014) whereby additional resources to schools are secured on evidence of a diagnosis of SEN. However, a new model of resource allocation is currently being piloted with a view to full implementation in 2017 (NCSE, 2014). It promises a move away from a deficit model of resource allocation to one requiring a social, collective response from schools. Schools' allocations will be based on a whole-school determination of need.

Internationally, inclusive education as a phenomenon is complex, highly contested and characterised by significant ambiguities (Dyson, 2009; Hegarty, 2001; Thomas and Loxley 2007). In Ireland it affirms the right of children with SEN to an appropriate education along a continuum of provision, while promoting placement in mainstream education where possible. An increasingly diverse student population in mainstream schools in Ireland has prompted 
changes to school organisation and necessitated a need for a coordinator of special and inclusive provision for learners with SEN. In 1993 there were 1,309 special education teachers working in mainstream primary and post-primary schools in Ireland (NCSE, 2014). Latest statistics indicate that more than 11,000 special education teachers currently work in mainstream schools (NCSE, 2015). In Ireland, the SENCO role has evolved in response to this rapidly transforming educational landscape where various interpretations co-exist alongside the often invisible work undertaken by SENCOs in environments under constant re/construction. While roles and responsibilities vary between SENCOs internationally, research indicates that the role is difficult (Cole, 2005; O'Gorman and Drudy, 2011; Oldham and Radford, 2011).

Defining the SENCO role: a challenge too great?

A discernible absence of SENCO role consistency is evident in various contexts and across time (Mackenzie, 2007; Wedell, 2006) yet research indicates that the role is difficult (Cole, 2005; O'Gorman and Drudy, 2011; Oldham and Radford, 2011). Variations in SENCO role enactment have led to a fluid definition of the position (Swzed, 2007). This in turn leads to difference in practice as the duties change over time (Cole, 2005; Layton, 2007). Exploring the professional learning of SENCOs, Kearns (2005) provides a helpful typology which acknowledges the varying approaches to the role:

- SENCO as Arbiter: focusing on helping others like teachers and parents feel positive about inclusion; negotiating, rationalising and monitoring the use of resources and using a range of information sources to facilitate colleagues' professional development. 
- SENCO as Rescue[r]: focusing intensely on individual teaching with individual learners with SEN; demonstrate great empathy and commitment while lacking interest in management or collaborative work with others.

- SENCO as Auditor: emphasis placed on the management and administration of special education provision; monitoring of learner progress, IEP management, record keeping with a focus on meeting legal requirements. This role suggests one which is purely managerial.

- SENCO as Collaborator: focusing on relationships with others; keen to share practice and engage in collaborative curriculum planning; tend to work in schools where distributed leadership is promoted and where SEN is established as a school-wide process.

- SENCO as Expert: focusing on the SENCO as specialist with additional qualifications in teaching learners with severe or specific disabilities;

There are challenges in formulating a SENCO identity (Cowne, 2005; Mackenzie, 2007; Pearson and Ralph, 2007; Rosen-Webb, 2011) and ambiguities surrounding the role appear to prohibit the development of a solid SENCO identity (Pearson and Ralph, 2007). The theory of the third space as an 'emergent territory between academic and professional domains' resonates with a domain occupied by SENCOs, who may not have a sense of belonging in any particular team (Whitchurch, 2008, p.386). Many are being called upon to create their own role and occupy a space that is unfamiliar to them and outside the boundaries of their expertise. SENCOs comprise a hybrid group of subject-specialists, who work in a context loosely defined by policy. The third space is characterised by fluidity, flexibility, creativity and a merging of identities where the dynamics can be harnessed in a positive way to help members construct unique and creative professional profiles (Whitchurch, 2008). From this perspective, SENCOs 
could move from a position of isolation and uncertainty, to one which fosters positivity towards this fluidity, flexibility and uniqueness.

There is no doubt that moves towards inclusive education have delivered increasing challenges to the SENCO role. The literature identifies the need to formalise the role, and supports the notion that the most senior teacher should be positioned on the school management team (Cole, 2005; O’Gorman and Drudy, 2011; Szwed, 2007; Tissot, 2013). While supporting and leading colleagues is identified as a responsibility, the complexity of the role, together with the enormity of the administrative burden on SENCOs (many of whom are isolated) prevents them from assuming more strategic, leadership duties such as coaching colleagues (Cole, 2005; Cowne. 2005; Garner, 2001; Layton, 2007; O’Gorman and Drudy, 2011). Furthermore, the role is often perceived as low status and operational in nature (Cole, 2005; Szwed 2007). Put simply, if SENCOs are spending increasing and often overwhelming amounts of time completing (invisible?) administrative tasks can the strategic nature of the role be developed?

As a response, responsibility for specified groups of students should not be seen to reside in one individual (Layton, 2005; Norwich, 2010). It is impossible for the SENCO to be singularly responsible for special education provision. Responsibilities must be distributed. In this way the SENCO can become a visionary providing leadership within the school (Blandford and Gibson, 2000; Norwich, 2010). The development of systems promoting inclusive education is imperative therefore, to allow SENCOs to act as figureheads without being burdened with administration and coordination of SEN for the entire school community (Hallett and Hallett, 2010; Oldham and Radford, 2011). Unlike other subject coordinators, SENCOs are required to work alongside colleagues while also trying to influence staff attitudes and practice (Busher and Harris, 2000), many of whom conceptualise inclusive education differently (Dyson, 1993; 
Hallett and Hallett, 2010). The word influence is significant. How can SENCOs positively influence the attitudes, values and practices of colleagues? In essence how do SENCOs become leaders of change in a 'leadership for learning' community (Swaffield and Macbeath, 2009)? The development of 'learning organisations' (Senge, 1990) and systems promoting collaborative practice provide an analytic for SENCO role enactment, where capacity to influence change is identified as a core skill and is dependent on the connections within and between networks or communities of practice (Wenger, 1998).

\section{Is there a need for the SENCO role?}

A tension exists between the SENCO role and an approach to inclusive education that supports a universal response. If special education is to be the responsibility of all, is there a need for the SENCO? In essence, isn't an effective SENCO one who works themselves out of a job? The development of a dual system of mainstream and special education in Ireland and elsewhere has led to 'the historical isolation of special education from mainstream education' (Griffin and Shevlin, 2011, p. 2).

Inclusive education in Ireland equates to steering students onto the exit ramp, withdrawing them from regular classrooms and their peers for special teaching, without any route map for return to their classrooms (Egan, 2013). It was (is?) assumed that children with SEN are intrinsically different to their peers and require esoteric pedagogy (Griffin and Shevlin, 2011). Educationalists variably describe what constitutes special teaching (Griffin and Shevlin, 2011; O’Murchu, 1996; Westwood, 2013) but essentially it relates to how teachers enable access to learning for students with SEN by means of appropriate methodologies, resources and materials and 'with an attitude that actualises all of this by way of a meaningful and empowering relationship with the learner' (O’Murchu in Griffin and Shevlin, 2011, p.113). 
Are SENCOs, by virtue of the position, perpetuating this dual system of special and mainstream education? It has also been argued that labels such as special educational need are incompatible with the philosophy of inclusion (Thomas and Loxley, 2007) but would developing the SENCO as a leader of learning and change or as a Collaborator (Kearns, 2005), operating within the third space inspire more inclusive practice at whole-school level (Dyson and Millward, 2000)? As a way forward for SENCOs it would mean letting go of individualism (isolation?) and embracing the creative and innovative dynamic generated through collaboration in this shared space. Maybe development of the SENCO as leader, mentor and collaborator could provide the much needed support for learners and staff while at the same time moving away from the idea of SENCO as Expert or Rescue (Kearns, 2005), entrenched in work with individual students and embedded in deficit views of student dis/ability.

A whole-school approach to special education, where the SENCO engages in collaborative practice at the classroom level could enhance inclusive practice and develop the pedagogical skills of all practitioners (Kugelmass; 2003). The focus is on the development of inclusive pedagogies to promote learning for all students. This empowers SENCOs to develop roles that were not bolted on (Norwich, 1993). Development of the SENCO role from this perspective embeds itself firmly in curricular and pedagogical issues, and facilitates the advancement of inclusive practice throughout the school and the wider community. In this regard, the SENCO becomes more agentive. However, developing SENCOs as leaders of change is dependent on a complex web of interdependent and interconnected variables such as context, school leadership, teacher competence, teacher attitudes, and SENCO status. 
Research outlines both leadership and management elements to the SENCO role (Rosen-Webb, 2011; Tissot, 2013). Leadership implies 'vision, mission and purpose coupled with a capacity to inspire others to work towards the achievement of these aims' (Bush and Bell 2002, p.3, in Winwood (2013, p.27). Management is the practical implementation of this vision. For SENCOs to lead the SEN agenda a vision for inclusion is important. However, developing the SENCO as leader may be challenging in the Irish context. If SENCOs are to influence wholeschool policy and practice in special education at all school levels-but particularly at postprimary level where leadership tends to be distributed (Gronn, 2009)-they need to be strategically placed within the school management structure (Cole, 2005; Layton, 2005; O'Gorman and Drudy, 2011; Wedell 2006). How can this be achieved in the Irish context when the role does not formally exist? Then again, membership of the management team is not a panacea to enhancing the status of SENCOs or influencing their capacity to lead change (Hallett and Hallett, 2010). So what is then? SENCOs need to develop what Tangen (2005) calls a change competence. His study concluded that while a philosophy of inclusion and disability-specific knowledge is necessary, it is not enough. Teachers should also be competent (and willing) to serve as change agents, and to participate in and lead development work as a regular part of their role.

Furthermore, a reconceptualisation of the interplay between leadership and learning, and how this might lead to leadership for learning is required to engage leaders in collaborative efforts to bring about change and not simply to enforce 'street level bureaucracy' (Lipsky, 1980 in Hallett and Hallett 2010, p.54)-responding to policy and legislative initiatives in a top down manner (Hallett and Hallett, 2010, p.54). Leadership for learning focuses on three levels of learning: student, professional and organisational (Swaffield and Macbeath, 2009). The key principle maintains that learning is for everybody, it is a complex activity which is dynamically 
linked to leadership in an ongoing cycle of action, participation, reflection and collective and collaborative practice. If a culture of learning and continuous professional growth is cultivated by school leaders, it becomes embedded in school practice and facilitates a flexible, wholeschool response to learner diversity.

\section{Method}

This is a mixed-methods exploratory study (Cresswell, 2011). The main tool was a questionnaire designed to generate both quantitative and qualitative data. A purposive sampling technique was applied (Cresswell, 2013). An initial scoping exercise was undertaken by the researchers in an attempt to increase the response rate (Mertens, 2010) where one of the researchers made initial telephone contact with SENCOs using the Department of Education and Skills database of schools. Questionnaires were posted to 43 SENCOs and 27 SENCOs responded, representing a response rate of 63 per cent (see Figure 1). While variances existed between participants (Figure 1) and their sites the study does not purport to generalise to the wider post-primary school population. Variance was achieved by stratifying the sample according to geographical location (urban/ rural); composition (boys/ girls/ mixed); socioeconomic grouping (mainstream post- primary schools participating in Delivering Equality of Opportunity in Schools initiative (DEIS)(DES, 2005)/ mainstream post- primary schools not participating in DEIS) and language (Irish/ English medium schools). Most SENCOs had teaching experience ranging from 11 and 20 years (11) and 21 and 30 years (8). However, 21 SENCOs had less than 10 years' experience as SENCO.

\section{Figure 1: Profiles of Participating SENCOs}

\section{The Questionnaire}


The participating SENCOs completed a lengthy postal questionnaire with both closed and open questions. The content of the questionnaire was developed using key themes from the literature and was adapted from a questionnaire used by O'Gorman and Drudy's (2011) in a study of the professional development needs of SEN teachers working in Ireland and also from a scale of perceived teacher efficacy to teach in inclusive classrooms (Sharma et al, 2012).

This study utilised a convergent parallel mixed methods design (Cresswell, 2009). Analysis of responses was both 'theory-driven' and 'data-driven' (Braun and Clarke, 2006, p.88). Specifically, coding was directed by themes emerging from the literature (e.g. SENCO identity, status, leadership). Other themes emerged from the data. The majority of items in the questionnaire (26 out of 40) comprised closed questions. Descriptive statistics was used to analyse quantitative data. Results are presented in the form of bar charts and pie charts and measures of central tendency. A thematic approach to coding of qualitative data was conducted on responses to open questions (Braun and Clark, 2006; 2013; Bazeley 2013) using six stages from the initial coding of responses through to the generation of final themes. Some open questions sought factual data (e.g. total allocation of additional support hours, contact teaching hours, numbers of SEN teachers and numbers of IEPs etc.) which were collated and tabulated. Qualitative responses to questions such as 'what motivates you in your role?' or 'how does having or not having a post of responsibility impact upon your role?' were collated and categorised into codes which were then mapped to overarching themes (Bazeley, 2013).

The research questions asked:

- What are the roles and responsibilities of SENCOs?

- Is there a policy/ practice gap in relation to how the SENCO role is enacted? 
- What do SENCOs perceive to be their role and how do they conceptualise it?

\section{Findings}

Using theory to inform the analysis, four predominant themes emerged from data:

1. The SENCO role is complex, substantial and primarily operational.

2. Having specialist knowledge relating to SEN is not enough to lead a whole school approach to inclusive practice.

3. No clear SENCO identity exists.

4. School leadership is critical in creating whole school approaches to inclusive education

Theme 1: The SENCO role is complex, substantial and primarily operational

The first research question sought information on SENCOs roles and responsibilities. Data illustrate that the administrative work associated to the SENCO role is substantial. Tasks such as record keeping, report writing, timetabling of additional support, identifying students with SEN, making applications for reasonable accommodations in exams, and liaison with external agencies were among those reported as the most important duties of SENCOs. Additional comments included 'I do all of this and teach fulltime'. Data suggest that the role requires significant management due to a burgeoning workload. As a result, many SENCOs are fulfilling operational roles. They are bogged down with administrative duties which, to some extent prevent the more strategic development of SEN from a whole-school perspective. The key duties identified by SENCOs as core components of the role are detailed in Table 1.

\section{Insert Table 1: SENCOs most important roles and responsibilities}


More than half the SENCOs executed the role without any post of responsibility yet maintained similar workloads to those with posts. Furthermore, two SENCOs were principals and undertook the role alongside leading the entire school. While some SENCOs were allocated posts of responsibility, the post wasn't necessarily exclusive to SEN as highlighted by one SENCO when he wrote 'I just got the A [Assistant-principal] post but SENCO is only a small part of my allocated duties'.

Responses to the open questions revealed how SENCOs coped with workload in different ways. They described a role that was overwhelming and stressful. One SENCO wrote: 'SEN coordination should be a post of responsibility in all schools; unfortunately [it] is not here. Loads \& loads of paperwork which I do unpaid for', Another described how 'I do not have a post, I haven't enough time in the day to do the role-stress levels very high trying to juggle Leaving Cert. honours English etc. with workload'.

When exploring the more strategic duties of the SENCO role, where SENCOs undertook tasks that lead the SEN agenda at a whole-school level, it was apparent that many tasks, including whole-school leadership of SEN, whole-school management of SEN, liaison with the principal and collaboration with colleagues, were important to most SENCOs. That said, little evidence of SENCOs embedded in curricular and pedagogical issues related to whole class teaching and learning was found in the data. Provision of staff development and implementation of the school plan on SEN were identified as the least important aspects of the role combined with a model of provision relying almost completely on withdrawal of students from regular classes. This may be suggestive of approaches which bring about a dual system of special/ mainstream education within schools. 
Three SENCOs indicated they acquired the role when the previous SENCOs with posts retired. One SENCO conveyed how 'my colleague retired two years ago. She had an Assistantprincipal post which was lost due to the moratorium. I have to coordinate in secret due to Union directives. This is extremely frustrating'.

In response to the second research question asking if a policy/ practice gap exists in relation to role enactment the short answer here is no. A comparative analysis of findings from the current study with the list of duties described in the Inclusion of Students with Special Educational Needs Post-Primary Guidelines (DES, 2007, p.71) indicates that policy does reflect practice. Of the tasks described within the Guidelines, SENCOs indicated that they undertook most of these and more. Remarkably, no DES guidance has been issued to specify how much time SENCOs would need to undertake these tasks. In the absence of any such direction, it could be assumed that to date little appreciation has been given as to the magnitude of the role.

Theme 2: Having specialist knowledge relating to SEN is not enough to lead a whole school approach to inclusive practice.

This theme, while relating to the first research question, emerged strongly from the data and reflects much of the current tensions within the discourse about developing the SENCO as a strategic leader promoting a universal approach or as a specialist advisor, providing esoteric instruction to students with SEN (Oldham and Radford, 2011; Rosen-Webb, 2011). Only ten SENCOs considered themselves to be experts in their role despite 21 holding a postgraduate qualification in special education. 
Findings suggest that development of systems promoting inclusive practice facilitates a universal approach. This is as important as expertise in special education. SENCOs in management positions in the school were better able to influence the development of wholeschool systems to promote inclusive education. Ten SENCOs claimed that the post of responsibility elevated awareness of SEN at a whole-school level and allowed them to lead SEN within the school by developing communicative and collaborative systems.

When asked what motivated SENCOs to do the job, responses consistently indicated high levels of job satisfaction when advocating for and working directly with learners with SEN in small groups and/ or individuals withdrawal settings (i.e. specialist role). The notion of the SENCO as a caring warrior (Cole, 2005) or as Rescue (Kearns, 2005) resonated with them: 'I saw a need for a teacher to voice the concerns of students with SEN and to ensure that their needs were met' declared one when asked what motivated her.

Theme 3: No clear SENCO identity exists.

In answering the third research question relating to how SENCOs conceptualise their role, no clear SENCO identity emerged from data and it appears that SENCOs occupy a third space. For 26 SENCOs, the post co-existed alongside other roles, such as subject teacher, year head and principal. Essentially, the SENCO role seemed to be bolted on (Norwich, 2010) to other existing roles and therefore conceptualisations of the role were indistinct. Only nine identified their primary role as SENCO, while the others predominantly viewed themselves as subject teachers, principals or SEN teachers, with additional responsibilities for SEN coordination. Notably, those in leadership positions in the school identified more strongly with the SENCO 
role and reported using their position to strategically develop inclusive practice in the school. These SENCOs were in the minority and could be described as Collaborators (Kearns, 2005). They were involved in coordinating SEN provision from a whole-school perspective and used their position to build systems that might promote a whole-school approach. Most SENCOs who came to the role as SEN teachers seemed more concerned with meeting the needs of individual learners (SENCO as Rescue, or SENCO as Expert: Kearns, 2005) rather than the strategic development of systems promoting inclusive practice and enabling colleagues to support learners with SEN. Table 2 illustrates the responses when rating participants' perceptions of their role showing an overwhelmingly positive sense of efficacy and satisfaction.

\section{Table 2: SENCO Role Perceptions}

Theme 4: School leadership is critical in creating whole school approaches to inclusive education.

The research questions in the current study did not explicitly seek to explore the importance of leadership, however this theme emerged strongly from the data. Leadership mattered on two counts: firstly, principals were fundamental to promoting whole-school approaches to inclusive education and secondly, SENCOs in management positions were more agentive in their capacity to develop whole-school systems.

All SENCOs felt supported by the principal, despite 14 having no recognised post of responsibility in the school and nine having full teaching loads of 22 hours. Table 3 offers a comparative analysis of the teaching loads of individual SENCOs with posts of responsibility. 
It illustrates the enormous disparity across schools and indicates that in many instances principals had allocated additional time to undertake duties associated with the SENCO role.

\section{Insert Table 3: SENCO Teaching Load}

While 13 SENCOs had posts of responsibility eight of these also claimed to have other coordinating responsibilities. While the majority of SENCOs claimed to lead SEN provision in schools, and work collaboratively with colleagues, implementation of the SEN policy, coordination of IEPs and provision of staff development were identified as some of the least important aspects of the role.

Although most SENCOs enjoyed their job, frustration at the lack of status also emerged. When asked what impact having a post or not having a post of responsibility had on the role they noted how a post would/did elevate the status of the role. 'I feel having a post would professionalise the role and acknowledge my work in the area, and significance of SEN provision more generally'. Another added 'It enables me to put in place procedures and practice to support students and parents; ensures SEN is on the agenda for all staff meetings and pastoral care meetings; helps with formal dissemination of information'. While a post could elevate status, time to execute duties (whether operational or strategic) was identified as an issue amongst all SENCOs as illustrated when one declared 'I have to stay late every day to keep up. Approximately 2 hours a day. I don't know if having a post would make a difference to that but it would provide recognition'.

\section{Discussion and Conclusion}


The SENCO role in Ireland has blindly evolved in response to accelerated policy reform which has transformed the educational landscape beyond recognition, with further transformation imminent. Formalisation of the SENCO role is timely. In 2013, the then Minister for Education in Ireland called for research which would help inform policy. This study, while small scale, offers a response to the Ministers' call and demonstrates the need to elevate the status of the role to the management structures within schools and corroborates findings from other studies (Layton, 2005; O’Gorman and Drudy, 2011; Oldham and Radford, 2011).

Where SENCOs held management posts, particularly at senior management level, they reported greater effectiveness in the role. This paper asserts the need for dedicated SENCO posts in all post-primary schools. However, this paper also acknowledges that elevation to the management team is not a panacea (Hallett and Hallett, 2010) for successful role enactment. While much of the literature speaks of the need for a SENCO with specialist knowledge who can advise staff and deliver instruction to specific groups of learners (Cole, 2005; Cowne, 2005; Layton, 2007) an emphasis on SENCOs leading whole school, universal approaches to SEN, over their specialist knowledge, only serves to heighten ambiguity relating to role enactment (Rosen-Webb, 2011) and demands competence in leadership.

Findings indicated that the models of support in schools were predominantly based on withdrawal for esoteric, specialist teaching. This preserves a deficit view of disabilityidentifying specific needs within learners who require (supposedly) highly specialised learning programmes. Consequently, the continued need for experts is conserved. While the SENCO as Expert (Kearns, 2005) is evident from the findings it creates a tension when interlocked with a discourse on inclusive pedagogy that promotes a move towards education for all (Florian and 
Black-Hawkins, 2011). This approach moves away from the notion of a bolted on curriculum (Norwich, 2010) for learners with SEN, to one where systems of inclusive practice are developed from a whole-school perspective to incorporate the learning needs for all learners, using a collective, whole-school approach (Ainscow and Sandill, 2010).

One possibility might involve the creation of networks or communities of practice (Ainscow and Sandill, 2010; Wenger, 1998) in and between schools, where colleagues collaborate, reflect, problem-solve and problem-pose together towards a collective goal which might not only inform the actions of colleagues but more importantly it may change the 'thinking that informs these actions', (Ainscow and Sandill, 2010, p. 403). If a universal response is cultivated in schools, the SENCO could act as a consultant, advising staff in relation to inclusive pedagogy (Arnaiz and Castejon, 2001). Such an approach would also diminish the need for a reliance on student withdrawal from their regular classes for specialist teaching. However, the caring warrior trait (Cole, 2005) applies to the findings and indicates that SENCOs derive great enjoyment from teaching students with SEN in small groups and/ or individual withdrawal settings. Encouraging greater collaborative and cooperative practice might be challenging for SENCOs. If SENCOs continue to cultivate a dual system of special/ mainstream learning because this motivates them in the role, how can inclusive education truly become a universal responsibility (Oldham and Radford, 2011)? Further research, which takes an in-depth exploration of the role could identify and analyse the dynamics in particular contexts in an attempt to understand how the SENCO role should be formulated.

This paper recommends continuous professional development for SENCOs which is specifically tailored to their needs as strategic 'system leaders' and not simply as specialists. 
While specialist knowledge of disabilities, policy, legislation and inclusive pedagogies related to SEN is essential to the role, findings suggest the skills and knowledge required to develop collaborative approaches to teaching and learning, ability to develop change competence (Tangen, 2005), and lead professional development initiatives in schools are equally important to lead a universal approach to SEN. In the UK, all SENCOs are required to undertake NASENCO training, a specific postgraduate award which supports the acquisition of competencies in the area of whole-school approaches to inclusive education. No such training exists in Ireland. The development of mandatory postgraduate professional development, flexibly delivered which targets all post-primary SENCOs is needed. This of course, has implications for school leaders, policy-makers, third level institutions and providers of professional development.

School improvement is linked to a school's collective capacity to respond to change (Senge, 1990). The impact of school-based learning and the importance of developing schools as collaborative 'learning organisations' (Senge, 1990) has received increasing attention in the discourse relating to school improvement and leadership within education. A metaphor to describe the role of inclusive principals as horticulturalist seems fitting. Inclusive principals nurture professional growth and development of all staff by engendering openness to new learning and enquiry. These constant gardeners need to plant seeds to grow inclusive curricular programmes and to challenge long held belief systems, to water those seeds that empower staff to take greater action, to nourish roots extending into the wider community by inviting parents and community involvement, and finally, to alter the flow of resources to better encourage growth. 
SENCOs participating in this study reported strong leadership and support from their principals. Principals are instrumental in creating leadership for learning (Swaffield and Macbeath, 2009) dynamics in schools. More than half the SENCOs in this study did not have a dedicated post. The role of the principal becomes even more important as a result, strategically placing them to enable development of inclusive practice and to nourish the growth of a strong system of roots from which the SENCO can grow to become a visionary leader. This study did not seek the views of principals, yet the importance of strong leadership emerged from data. Future research should explore the perspectives of principals on effective whole-school approaches to inclusive education, with a particular emphasis on coordination of special education provision in schools.

\section{Final thoughts}

Our study indicates that the SENCO role is complex. Furthermore, SENCOs are largely fulfilling roles that are operational; partly arising from the weighty administrative burden but moreover, relating to the status attributed to the role in schools and lack of formal recognition of the role. Where SENCOs held posts of responsibility within the school management structures, SENCOs reported greater opportunity to lead. Yet, on closer inspection, strategic leadership of SEN did not occur in most cases.

This paper proposes that SENCOs had little agency to effect changes to whole-school inclusive practice. Nevertheless, much evidence is provided to indicate the importance of principals in promoting collaborative and cooperative practice within schools, which in turn impacts on SENCO role enactment.

Finally, the paper acknowledges that schools are faced with increasing diversity. Advancing the inclusive education agenda necessitates a collective response. SENCOs need to be 
repositioned to enable the construction of the third space. This paper acknowledges the challenges encountered and potential possibilities when occupying this space. While many may resist the development of collaborative practice in favour of individualism, the shared space represents a starting point, a common ground from which to evolve. Essentially, it represents a means by which schools negotiate dilemmas and challenges and not a solution.

\section{Word Count: 6991}

\section{References}

Ainscow, M. and Sandill, A. (2010). 'Developing inclusive education systems: the role of organisational cultures and leadership'. International Journal of Inclusive Education, 14(4), 401-416.

Arnaiz, P. and Castejon, J.L. (2001). 'Towards a change in role of the support teacher in Spanish education system' in European Journal of Special Needs Education, 16(2), 99-110.

Blandford, S. and Gibson, S. (2000). Middle Management in Schools: A Special Educational Needs Perspective. http://www.leeds.ac.uk/educol/documents/00001621.htm [Accessed: 14th October 2014].

Braun, V. and Clarke, V. (2006). Using Thematic Analysis in Psychology. Qualitative Research in Psychology, 3, 77-101. 
Busher, H. and Harris, A. (2000). Subject Leadership and School Improvement. London: Paul Chapman.

Cole, B.A. (2005). 'Mission Impossible? Special educational needs, inclusion and the reconceptualization of the role of the SENCO in England and Wales'. European Journal of Special Needs Education, 20(3), 287-307.

Cowne, E. (2005) 'What do special educational needs co-ordinators think they do?' Support for Learning, 20 (2), 61-68.

Department for Education (1994). Code of Practice on the Identification and Assessment of Special Educational Needs. UK: Central Office of Information.

Department of Education and Science (DES) (2007). Inclusion of Students with Special Educational Needs: Post-primary Guidelines. Dublin: Stationary Office

Dyson, A. (1993). 'Do we really need special needs coordinators?' in J. Visser and G. Upton (eds) Special Education in Britain after Warnock. London: David Fulton Publishers.

Dyson, A. (2009). 'Philosophy, politics and economics? The story of inclusive education in England' in D. Mitchell (ed.)(2009) Contextualising Inclusive Education. London: Routledge. Dyson, A. and Millward, A. (2000). Schools and Special Needs; Issues of Innovation and Inclusion. London: Paul Chapman.

Egan, M. (2013). Inclusive Education Policy, the General Allocation Model and Dilemmas of Practice in Primary Schools. Unpublished PhD Thesis. Cork: University College Cork.

Florian, L. and Black-Hawkins, K. (2011). 'Exploring inclusive pedagogy'. British Educational Research Journal, 37(5), 813-828. 
Griffin, S. and Shevlin, M. (2011). Responding to Special Educational Needs: An Irish Perspective. ( $2^{\text {nd }}$ edition). Dublin: Gill and MacMillan.

Gronn, P. (2009) 'From distributed to hybrid leadership practice', in A. Harris (ed.) Distributed Leadership: different perspectives. London: Springer.

Hallett, F. and Hallett, G. (2010). 'Leading learning: the role of the SENCO', in F. Hallett and G. Hallett (eds) (2010) Transforming the Role of the SENCO: achieving the award for SEN coordination. Maidenhead: Open University Press.

Hegarty, S. (2001). 'Inclusive education-a case to answer'. Journal of Moral Education, 30(3), 243-249.

Kearns, H. (2005). 'Exploring the Experiential Learning of Special Educational Needs Coordinators'. Journal of In-service Education, 31(1), 131-151.

Kugelmass, J. (2003). Inclusive Leadership; Leadership for Inclusion. London: National College for School Leadership.

Layton, L. (2005). 'Special Educational Needs Co-ordinators and Leadership: A Role Too far?'. Support For Learning, 20(2), 53-60.

MacKenzie, S. (2007). 'A review of recent developments in the role of the SENCO in the UK'. British Journal of Special Education, 34(4), pp.212-218.

National Council for Special Education (2014). Delivery for Students with Special Educational Needs: A better and more equitable way. Trim: NCSE.

Norwich, B. (2010). 'What implications do changing practices and concepts have for the role of SEN coordinator?' In Hallett, F. and Hallett, G. (eds) Transforming the Role of the SENCO: 
Achieving the National Award of SEN Coordination. Berkshire: McGraw-Hill/Open University Press.

O'Gorman, E. \& Drudy, S. (2011). Professional Development for Teachers Working in the Area of Special Education/Inclusion in Mainstream Schools: The Views of Teachers and Other Stakeholders. [Online] Submitted to the National Council for Special Education. Available at: www.ncse.ie/research/researchreports.asp SERI(2006). Last accessed 21st October 2014.

Oldham, J. and Radford, J. (2011). 'Secondary SENCO leadership: a universal or specialist role?'. British Journal of Special Education, 38 (3), 126-134.

O’Mhurcu, E. (1996). 'What is special about education?', Irish Educational Studies, 15, 252270.

Pearson, S. and Ralph, S. (2007). 'The identity of SENCOs: insights through images'. Journal of Research in Special Educational Needs, 7 (1), 36-45.

Rosen-Webb, S. (2011) 'Nobody tells you how to be a SENCO', British Journal of Special Education, 38(4), pp.159-168.

Senge, P.M. (1989). The fifth discipline: The art and practice of the learning organisation. London: Century.

Sharma, U., Loreman, T., and Forlin, C. (2012). 'Measuring teacher efficacy to implement inclusive practices'. Journal of Research in Special Educational Needs, 12(1), 12-21.

Swaffield, S.and Macbeath, J. (2009). 'Leadership for Learning' in J. Macbeath and N. Dempster (eds.) Connecting leadership and learning: principles for practice. London: Routledge. 
Szwed, C. (2007). 'Remodelling policy and practice: the challenge for staff working with children with special educational needs'. Educational Review, 59 (2), 147-160.

Tangen, R. (2005). 'Promoting inclusive education in secondary school in Norway: a national programme for teacher development' in European Journal of Special Needs Education, 20(1), $57-70$.

Thomas, G. and Loxley, A. (2007). Deconstructing Special Education and Constructing Inclusion. Buckingham: Open University Press.

Wedell, K. (2006). 'SENCOs' role in implementing inclusion policy: points from the SENCOForum', British Journal of Special Education, 33(4), 220-232.

Wenger, E. (1998). Communities of Practice: Learning, Meaning, and Identity. UK: Cambridge University Press.

Westwood, P., S. (2013). Commonsense methods for children with special educational needs. UK: Taylor \& Francis.

Whitchurch, C. (2008). 'Shifting Identities and Blurring Boundaries: the Emergence of Third Space Professionals in UK Higher Education.’ Higher Education Quarterly, 62 (4), 377-396. Winwood, J. (2013). Policy into Practice: The Changing Role of the Special Educational Needs Coordinator in England. Unpublished EdD Thesis. Birmingham: University of Birmingham. 
Table 1: SENCOs' identified most important roles and responsibilities

\begin{tabular}{|c|c|c|}
\hline Role \& Responsibility & $\begin{array}{l}\text { Mean SENCO } \\
\text { Response }\end{array}$ & $\begin{array}{l}\text { Mode SENCO } \\
\text { Response }\end{array}$ \\
\hline Liaison with principal on SEN issues & 1.78 & 1 \\
\hline $\begin{array}{l}\text { Liaison with National Educational } \\
\text { Psychological Service }\end{array}$ & 1.78 & 1 \\
\hline Record keeping & 1.78 & 1 \\
\hline Identification of students with SEN & 1.81 & 1 \\
\hline Staff consultant on SEN issues & 1.85 & 1 \\
\hline $\begin{array}{l}\text { Applications for Reasonable } \\
\text { Accommodations in Certified Exams }\end{array}$ & 1.93 & 1 \\
\hline Report Writing & 1.96 & 2 \\
\hline Collaborating with other teachers & 2.04 & 1 \\
\hline Liaison with parents & 2.07 & 1 \\
\hline Timetabling of additional support & 2.11 & 1 \\
\hline Whole-school leadership in SEN & 2.15 & 1 \\
\hline $\begin{array}{l}\text { Whole-school management and } \\
\text { responsibility for SEN }\end{array}$ & 2.15 & 1 \\
\hline $\begin{array}{l}\text { Withdrawal of students for small group } \\
\text { instruction }\end{array}$ & 2.23 & 1 \\
\hline Implementation of school plan on SEN & 2.30 & 3 \\
\hline Formulation of school plan on SEN & 2.33 & 1 \\
\hline $\begin{array}{l}\text { Withdrawal of students for individual } \\
\text { instruction }\end{array}$ & 2.37 & 1 \\
\hline
\end{tabular}


Table 2: SENCO Role Perceptions

\begin{tabular}{|c|c|c|c|c|}
\hline Statement & $\begin{array}{l}\text { Agree/ } \\
\text { Strongly } \\
\text { Agree }\end{array}$ & Undecided & $\begin{array}{l}\text { Disagree/ } \\
\text { Strongly } \\
\text { Disagree }\end{array}$ & Total \\
\hline I am confident in my role. & 24 & 3 & 0 & 27 \\
\hline I enjoy my role. & 26 & 1 & 0 & 27 \\
\hline $\begin{array}{l}\text { I consider myself an 'expert' in special } \\
\text { education. }\end{array}$ & 10 & 12 & 5 & 27 \\
\hline $\begin{array}{l}\text { Others in the school consider me an } \\
\text { 'expert' in special education. }\end{array}$ & 20 & 5 & 2 & 27 \\
\hline $\begin{array}{l}\text { I am effective in my role as SEN } \\
\text { coordinator. }\end{array}$ & 19 & 7 & 1 & 27 \\
\hline I am an effective teacher. & 25 & 2 & 0 & 27 \\
\hline $\begin{array}{l}\text { I can make learning accessible for all } \\
\text { students in my classroom. }\end{array}$ & 25 & 1 & 1 & 27 \\
\hline $\begin{array}{l}\text { I can improve the learning of a student } \\
\text { who is failing. }\end{array}$ & 27 & 0 & 0 & 27 \\
\hline $\begin{array}{l}\text { I can make parents feel comfortable } \\
\text { coming to school. }\end{array}$ & 26 & 1 & 0 & 27 \\
\hline $\begin{array}{l}\text { I can assist families in helping their } \\
\text { children do well in school. }\end{array}$ & 26 & 1 & 0 & 27 \\
\hline $\begin{array}{l}\text { I am confident to offer advice to other } \\
\text { teachers about students with special } \\
\text { educational needs. }\end{array}$ & 25 & 2 & 0 & 27 \\
\hline $\begin{array}{l}\text { I can collaborate with other professionals } \\
\text { in designing educational plans for } \\
\text { students with disabilities. }\end{array}$ & 23 & 4 & 0 & 27 \\
\hline $\begin{array}{l}\text { There is strong leadership in my school } \\
\text { that promotes a whole-school approach } \\
\text { to inclusion }\end{array}$ & 24 & 3 & 0 & 27 \\
\hline I feel supported by the principal. & 26 & 1 & 0 & 27 \\
\hline $\begin{array}{l}\text { Staff in my school are committed to } \\
\text { providing inclusive education to students } \\
\text { with special educational needs. }\end{array}$ & 20 & 5 & 2 & 27 \\
\hline
\end{tabular}


Table 3: SENCO Teaching Load

\begin{tabular}{|c|c|c|}
\hline SENCO \# & Contact Teaching Hours & Post of Responsibility \\
\hline 1 & 22 & No Post \\
\hline 2 & 6 & Principal \\
\hline 3 & 22 & No Post \\
\hline 4 & 20 & Special-duties \\
\hline 5 & 0 & Assistant-principal \\
\hline 6 & 18 & Assistant-principal \\
\hline 7 & 19 & No Post \\
\hline 8 & 22 & Assistant-principal \\
\hline 9 & 16 & No Post \\
\hline 10 & 22 & No Post \\
\hline 11 & 0 & Principal \\
\hline 12 & 22 & Special-duties \\
\hline 13 & 0 & Deputy Principal \\
\hline 14 & 17 & Assistant-principal \\
\hline 15 & 18 & Special-duties \\
\hline 16 & 12 & No Post \\
\hline 17 & 18 & No Post \\
\hline 18 & 18 & No Post \\
\hline 19 & 19 & Assistant-principal \\
\hline 20 & 22 & No Post \\
\hline 21 & 22 & No Post \\
\hline 22 & 21 & No Post \\
\hline 23 & 22 & Assistant-principal \\
\hline 24 & 21 & Special-duties \\
\hline 25 & 20 & No Post \\
\hline 26 & 22 & No Post \\
\hline 27 & 21 & No Post \\
\hline
\end{tabular}




\section{Figures}

Figure 1: Profiles of Participating SENCOs

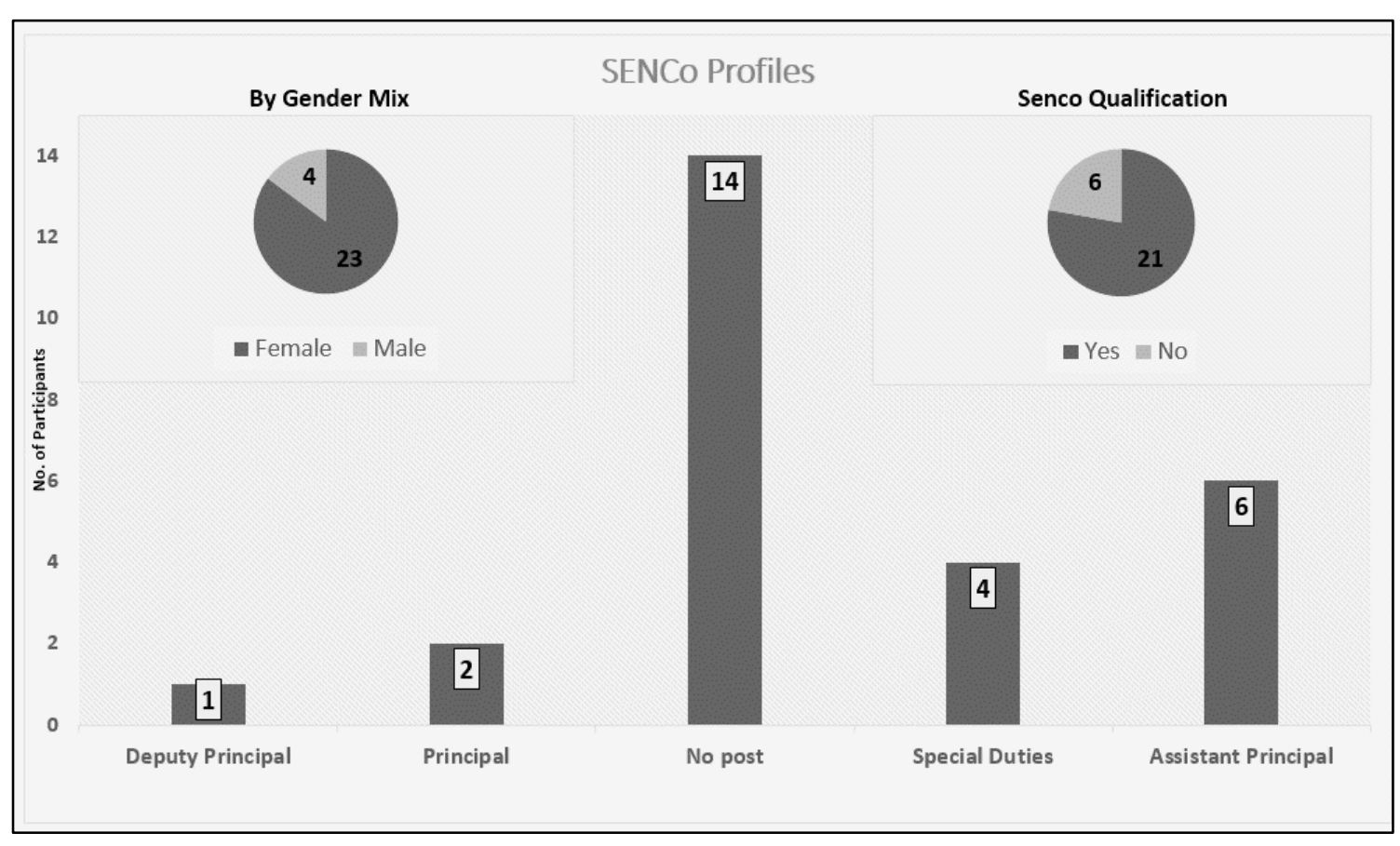

